\title{
CHARACTERIZATION OF ZrO2 FOR APPLICATION IN DENTAL IMPLANTS
}

\author{
Medeiros, L. A. D. M. ; Cardoso, M. J. B ${ }^{1 *}$; Farias, K. A. S. ; Lima, R. J. S. ${ }^{1,2 ;}$ Fook, \\ M. V. L. 1 \\ ${ }^{1}$ CERTBIO, Academic Unit of Materials Engineering, Federal University of Campina Grande, Campina Grande, Paraiba, Brazil \\ ${ }^{2}$ Academic Unit of Physics, Federal University of Campina Grande, Campina Grande, Paraiba, Brazil \\ *marcioufcg@gmail.com
}

\begin{abstract}
Ceramic biomaterials have been largely applied as a means for replacement and / or repair of biological tissue such as orthopedic and dental implants, grafts, among others, because they have similarity shown with bone tissue, chemical stability, high hardness and wear resistance. Among these, we highlight the zirconia, for possessing biocompatibility without mutagenic effects, bacterial adhesion and better periointegration. The development of a porous zirconia aims to enhance the biological properties of this ceramic in order to optimize and accelerate osteointegration. The zirconium oxide $\left(\mathrm{ZrO}_{2}\right)$ used was obtained commercially and produced by the method of chemical decomposition. The Structural characterization of $\mathrm{ZrO}_{2}$ powder will be held by the techniques of X-ray Diffraction (XRD) and Rietveld refinement method, optical microscopy (OM), scanning electron microscopy (SEM) and energy dispersive spectroscopy (EDS). Preliminary results of XRD and Rietveld refinement, indicate the presence of crystalline phases in nanometric dimensions tetragonal and monoclinic $\mathrm{ZrO}_{2}$ with concentrations of $71 \%$ and $29 \%$, respectively. The tetragonal phase, which has improved properties, only exists at room temperature, due to the presence of substitutional of yttrium, in this case $10 \%$. Preliminary results indicate that the $\mathrm{ZrO}_{2}$ used, has excellent characteristics for the application of dental implants.
\end{abstract}

